\title{
Kinetics of mixing-water repartition in UHPFRC paste and its effect on hydration and microstructural development
}

\author{
Hadi Kazemi-Kamyab ${ }^{\mathrm{a}, \mathrm{b}, *}$, Arnaud Charles Albert Muller ${ }^{\mathrm{a}, 1}$, Emmanuel Denarié ${ }^{\mathrm{b}}$, \\ Eugen Brühwiler ${ }^{\mathrm{b}}$, Karen Scrivener ${ }^{\mathrm{a}}$ \\ a Laboratory of Construction Materials (LMC), Swiss Federal Institute of Technology (EPFL), Station 12, CH-1015 Lausanne, Switzerland \\ ${ }^{\mathrm{b}}$ Laboratory of Maintenance and Safety of Structures (MCS), Swiss Federal Institute of Technology (EPFL), Station 18, CH-1015 Lausanne, Switzerland
}

A R T I C L E I N F O

\section{Keywords:}

UHPFRC

${ }^{1}$ HNMR

MIP

Hydration degree

XRD

RPC

UHPC

\begin{abstract}
A B S T R A C T
The hydration of an ultra-high performance fibre reinforced concrete (UHPFRC) paste with a water to cement ratio of 0.18 was followed by proton nuclear magnetic resonance ( ${ }^{1} \mathrm{H}$ NMR) alongside more classical techniques for hydration kinetics, and microstructural analysis. The states of water were quantified at different times by following the repartition of the "mixing water" after casting into "capillary water, gel water, CSH interlayer water and solid water" as hydration takes place. It was found that the capillary water is quickly depleted, and subsequently hydration continues with the consumption of the gel water. Overall the material becomes extremely self-desiccated with all water, bound in crystalline hydrates and the interlayer of C-S-H.
\end{abstract}

\section{Introduction}

Ultra-high performance fibre reinforced cementitious composites have become known as efficient materials in the novel design of new structures and enhancement of existing structures [1] because of their distinct material behavior. On one hand, the matrix of UHPFRC has exceptional durability properties due to its very low permeability, and on the other hand, the use of a fibrous mix (dosage and aspect ratio) adapted to the matrix can provide high tensile strength (typically $>$ $10 \mathrm{MPa}$ ) with significant strain hardening response [2,3].

The very low permeability to gases and liquids ([4,5]) and high compressive strength $\left(f_{c}\right.$ higher than $\left.150 \mathrm{MPa}\right)$ of UHPFRC stems from its very high packing density, extremely low water/binder ratio (typical UHPFRC mix has $w /$ fines $<0.2$, high content of cement (typically $>$ $800 \mathrm{~kg} / \mathrm{m}^{3}$ ), $18 \%$ to $26 \%$ of silica fume by mass, and significant amount of superplasticizer which results in very low porosity. The physical and chemical contributions of the mix design to the pore structure come from:

(a) The geometrical optimization of the particle size distribution [6] down to the sub mm range, and the high amount of ultrafine particles such as silica fume which contribute to increase of the packing density through micro- and nano-filling of the solid matrix $[7,8]$. (b) The very low water to binder ratio $(\mathrm{w} / \mathrm{b}<0.2)$. This means that there are only small distances between the solid particles, which can quickly be bridged by the hydration products.

(c) Furthermore, the pozzolanic reaction [9-11], and the filler effect [12-15] from the supplementary cementitious materials (SCMs) such as silica fume will form more C-S-H, further infilling the pore structure.

Various attempts have been made to quantify the evolution of the porous network and the microstructural development in UHPFRCs. However, most reports have been on the characterization of porosity in matured samples. Few researchers have tried investigating the evolution of the pores in UHPFRC as hydration takes place [16-18]. Morin et al. [17] reported that there are two main pore size ranges observed as hydration takes place in a UHPFRC paste with $w / c=0.21$ and $25 \%$ silica fume content by mass. At the beginning of the hydration (39 to $40 \mathrm{~h}$ after water addition), most pores are in the range $10-20 \mathrm{~nm}$. As the hydration continues, these pores are filled with hydration products and subsequently, most of the porosity lies in the range $1-2 \mathrm{~nm}(70 \mathrm{~h}$ onward). This characterization was based on a model from ultrasonic velocity and autogenous shrinkage measurements. Touse et al. [18] investigated the pore structure of UHPFRC paste with water/powder ratio of 0.18 and various amount of silica fume: $0 \%, 6 \%, 18 \%$ and $24 \%$ using mercury intrusion porosimetry (MIP) at various hydration times.

\footnotetext{
* Corresponding author current address: VITO NV, Sustainable Materials Management Unit, Boeretang 200, 2400 Mol, Belgium.

E-mail address: Hadi.Kamyab@vito.be (H. Kazemi-Kamyab).

${ }^{1}$ Current address: HeidelbergCement AG, Oberklamweg 2-4, 69181 Leimen, Germany.
} 
The threshold radius was lower as the percentage of silica fume increased; furthermore the shape of the cumulative pore volume curves changed as the amount of silica fume was increased in the mix. Despite these earlier studies, there is still limited insight about the processes involved in the development of porosity and microstructure of UHPFRC, especially regarding the development of the pore network at early age.

Hydrogen proton nuclear magnetic resonance $\left({ }^{1} \mathrm{H}\right.$ NMR) relaxometry provides the means to directly probe the states of water in evolving pore structures of cementitious materials [19,20]. It is noninvasive and non-destructive so the same sample can be measured over the course of hydration. The first study of a UHPFRC matrix $(w /$ $c=0.15$ ) by ${ }^{1} \mathrm{H}$ NMR was by [19]. The experiment was carried out on a heat treated sample at $90^{\circ} \mathrm{C}$ for $48 \mathrm{~h}$. By interpreting the spin lattice relaxation times $\left(T_{1}\right)$, two pore size ranges were identified: $9.6-11.6 \mathrm{~nm}$ and 1.4-1.7 nm. In another study Porteneuve et al. [10] used ${ }^{1} \mathrm{H}$ NMR and ${ }^{29} \mathrm{Si}$ solid NMR to investigate how the pore size distribution was affected by 1) the specific surface area of the silica fume used, and 2) the filling ratio which was defined as the ratio of the volume of fine particles between the cement grains over the volume of voids between the cement grains. Three different UHPFRC mixes were considered. However, the samples were heat cured and that experiments were carried out on one-month-old samples. Consequently, information is still missing about the hydration development of UHPFRC cured at room temperature.

Recently Muller et al. [21] showed that ${ }^{1} \mathrm{H}$ NMR relaxometry can quantify all the water in hydrating cement samples and that water can be unambiguously assigned to (1) water bound in "solid" calcium hydroxide and alumina containing hydrates (AFt, AFm), (2) C-S-H interlayer water, (3) water in the C-S-H "gel pores" and (4) capillary water. With ${ }^{1} \mathrm{H}$ NMR, quantitative information could be obtained about the hydration mechanisms from the perspective of the water.

In this paper ${ }^{1} \mathrm{H}$ NMR was used to study the repartition of the mixing-water as hydration takes place in a UHPFRC paste. Other methods were used to complement the ${ }^{1} \mathrm{H}$ NMR results and understand how the repartition of water affects the hydration and microstructural evolution. Isothermal calorimetry was used to follow the heat of hydration, X-ray diffraction (XRD) with Rietveld refinement and thermogravimetry (TG) were used to follow the development of phases. The microstructural evolution was studied by scanning electron microscopy (SEM) and MIP was used to investigate the development of the pore network. The relation between the hydration and the evolution of the porous network and the compressive strength is discussed.

\section{Materials and methods}

\subsection{Materials}

The formulation of the UHPFRC studied is given in Table 1. Fibres were omitted from the mix. First because ${ }^{1} \mathrm{H}$ NMR measurements cannot be conducted with steel fibres due to paramagnetic susceptibility; and second because the small amount of material required for
Table 2

Physicochemical properties of the raw materials used.

\begin{tabular}{llll}
\hline Oxide comp. (wt\%) & Cement & Silica fume & Sand \\
\hline $\mathrm{SiO}_{2}$ & 22.44 & 92.51 & 98.41 \\
$\mathrm{Al}_{2} \mathrm{O}_{3}$ & 2.76 & 2.89 & 0.46 \\
$\mathrm{Fe}_{2} \mathrm{O}_{3}$ & 2.24 & 0.18 & 0.06 \\
$\mathrm{CaO}$ & 68.05 & 0.04 & 0.03 \\
$\mathrm{MgO}$ & 0.91 & 0.04 & 0.05 \\
$\mathrm{SO}_{3}$ & 2.25 & 0.00 & 0.00 \\
$\mathrm{Na}_{2} \mathrm{O}$ & 0.19 & 0.24 & 0.12 \\
$\mathrm{~K}_{2} \mathrm{O}$ & 0.11 & 0.13 & 0.47 \\
$\mathrm{TiO}_{2}$ & 0.14 & 0.03 & 0.06 \\
$\mathrm{P}_{2} \mathrm{O}_{5}$ & 0.09 & 0.03 & 0.07 \\
$\mathrm{Mn}_{2} \mathrm{O}_{3}$ & 0.03 & 0.01 & 0.00 \\
$\mathrm{ZrO}_{2}$ & 0.10 & 2.76 & 0.16 \\
$\mathrm{Cr}_{2} \mathrm{O}_{3}$ & 0.01 & 0.00 & 0.00 \\
$\mathrm{LOI}\left(950^{\circ} \mathrm{C}\right)$ & 1.28 & 0.61 & 0.08 \\
$\mathrm{Specific} \mathrm{surface} \mathrm{area}^{2} / \mathrm{g}(\mathrm{BET})$ & 0.94 & 12.00 & - \\
Density $\left(\mathrm{g} / \mathrm{cm}^{3}\right)$ & 3.15 & 2.2 & 2.7 \\
\end{tabular}

the experiments makes the use of fibres impractical. It can be assumed that the removal of the fibres does not significantly influence the kinetics of hydration. The mix design given in Table 1 was used for the compressive strength testing. The microstructural studies were carried out on pastes without sand.

The binder is defined as cement plus silica fume (SF). The total water content takes into account the water in the superplasticizer. The chemical composition of the cement, silica fume, and sand were determined by X-ray fluorescence (XRF) and are shown in Table 2. The Brunauer-Emmet-Teller (BET) specific surface areas of the cement and silica fume given in Table 2 were obtained by nitrogen gas at liquid nitrogen temperature using Micromeritics Gemin 2375 V4 instrument; Note that degassing conditions of $40^{\circ} \mathrm{C}$ under $\mathrm{N}_{2}$ for $16 \mathrm{~h}$ were used [22]. Table 3 shows the phase composition of the cement based on Bogue calculation and by Rietveld analysis. The particle size distribution of the cement, silica fume, and sand were measured using Malvern Mastersizer type $S$ laser beam granulometer, and are shown in Fig. 1.

For all experiments, a $51,0.35 \mathrm{~kW}$, Type 32 Perrier paddle mixer was used for mixing. The volume of fabricated UHPFRC matrix was 11 . All the solid components (cement, silica fume, and sand) were first added to the bowl, and then mixed dry for $2.5 \mathrm{~min}$ at $60 \mathrm{rpm}$; while the mixer was running, deionized water and the superplasticizer were added and all the materials were mixed together for $4 \mathrm{~min}$ at $60 \mathrm{rpm}$. The mixer was stopped and the materials scrapped down into the bowl. Then the material was mixed for 4 min with the speed of $123 \mathrm{rpm}$. All samples were sealed cured at $20^{\circ} \mathrm{C}$.

\subsection{Methods}

${ }^{1} \mathrm{H}$ NMR experiments were carried out at intervals throughout hydration to monitor the state of water in the developing microstructure of the UHPFRC pastes. The ${ }^{1} \mathrm{H}$ NMR measurements were carried out using Bruker Minispec NMR spectrometer operating at 7.5 MHz. The

Table 1

Mix of UHPFRC paste with description of the components used. This mix design was used for the compressive strength testing. The microstructural studies were carried out on pastes without sand.

\begin{tabular}{|c|c|c|}
\hline Components & Description & UHPFRC paste $\left(\mathrm{kg} / \mathrm{m}^{3}\right)$ \\
\hline Cement & CEM I 52.5 N CE PM-ES-CP2 NF from Lafarge (Le Teil) & 1142 \\
\hline Sand & Fontainebleau type MN30 Quartz; $\mathrm{D}_{\max }<0.5 \mathrm{~mm}$ & 663 \\
\hline Silica fume & Zirconium silica fume from SEPR & 297 \\
\hline Superplasticizer & Superplasticizer from TKK (SL); Zementol zeta super S.; polycarboxylate; $25 \%$ solids content & 10 \\
\hline Total water & & 206 \\
\hline Total & & 2317 \\
\hline Water/cement & & 0.180 \\
\hline Water/binder & & 0.143 \\
\hline
\end{tabular}


Table 3

Cement phases using Bogue calculation \& Rietveld analysis.

\begin{tabular}{lll}
\hline Phase & Bogue (mass \%) & Rietveld (mass \%) \\
\hline $\mathrm{C}_{3} \mathrm{~S}$ & 60.6 & 62.3 \\
$\mathrm{C}_{2} \mathrm{~S}$ & 19.5 & 20.2 \\
$\mathrm{C}_{3} \mathrm{~A}$ & 3.9 & 1.4 \\
$\mathrm{C}_{4} \mathrm{AF}$ & 5.7 & 5.8 \\
Lime $(\mathrm{CaO})$ & - & 0.6 \\
Calcite & - & 2.6 \\
Quartz & - & 0.1 \\
Gypsum & - & 0.8 \\
Bassanite & - & 2.1 \\
Anhydrite & - & 1 \\
\hline
\end{tabular}

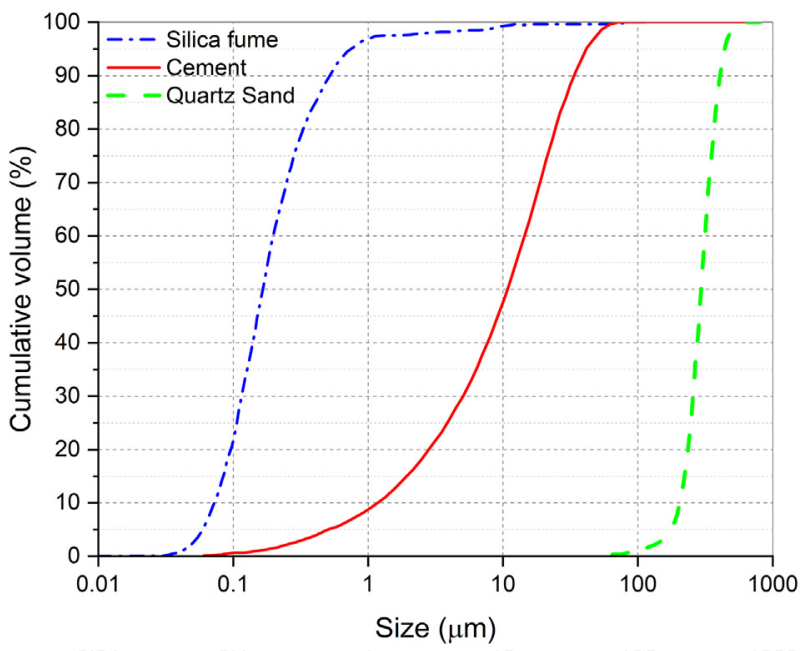

Fig. 1. Particle size distribution of the raw materials measured by laser granulometry.

$90^{\circ}$ pulse was $2.92 \mu$ s. Quadrature (or solid) echo measurements [23] and CPMG (spin) echo measurements [24] were made. Immediately after mixing, approximately $1 \mathrm{~g}$ of paste sample was placed into the NMR glass tube. A glass rod with approximately the same diameter as the inner diameter of the tube was inserted in the tube just up to the top of the fresh sample to ensure the sample is well sealed. The opening of the tube was tightly sealed with Parafilm ${ }^{\circledast}$. Samples were measured at intervals from mixing up to 7 days of sealed hydration at $20^{\circ} \mathrm{C}$.

In the case of the quadrature echo (QE), signals were recorded as a function of pulse gap in the range of $\tau=15-45 \mu \mathrm{s}$. The output signals were deconvoluted into a Gaussian and an exponential decay part [25]. The Gaussian part of the signal with a very short time constant of approximately $10 \mu$ s was assigned to water in crystalline solid phases Portlandite and ettringite. The exponential part of the signal was attributed to liquid water within pores. Following the work of Muller et al. [21], the mass fraction of solid-like hydrogen within the sample was back extrapolated to zero pulse gap using Gaussian extrapolation. In parallel, the different populations of liquid water were separately resolved into different $T_{2}$ components using the CPMG pulse sequence. The signal was inverted using the Laplace inverse transform (ILT) algorithm developed by Venkataramanan et al. [26].

The kinetics of hydration were followed using Isothermal calorimetry. A TAM AIR isothermal calorimeter from TA Instruments was used to measure the heat flux released from the sample at $20^{\circ} \mathrm{C}$. Immediately after the mixing, approximately $12 \mathrm{~g}$ of paste was placed into a $20 \mathrm{ml}$ glass ampoule. The ampoule was sealed and then inserted in the calorimetry. Measurements were made over 28 days.

The internal relative humidity evolution due to hydration was followed using a HC2-AW water activity probe by Rotronics. The global accuracy of the sensor was $\pm 0.8 \%$ RH and $\pm 0.1^{\circ} \mathrm{C}$. After approximately $27 \mathrm{~h}$, when the UHPFRC paste has passed setting time, a sample cured under sealed conditions at $20^{\circ} \mathrm{C}$ was broken into pieces of $5-10 \mathrm{~mm}$ and placed in a small plastic dish which goes into the compartment of the RH instrument. The sensor is inserted into the compartment, and placed just above the dish. The sensor is then locked in position and the compartment sealed. The pieces from the paste sample remain at $20^{\circ} \mathrm{C}$, as the casing is equipped with cooling circuits attached to a water bath at $20^{\circ} \mathrm{C}$. In addition, the whole system is isolated by a polystyrene foam box to have better thermal-hygral insulation. Measurements were carried out at $1 \mathrm{~min}$ intervals over 28 days. Note that before and after the experiment, various saturated salt solutions between $98 \%$ to $60 \%$ relative humidity were used to verify that the sensor was well calibrated.

For the microstructural characterization techniques: (TG, MIP, SEM, and XRD), paste, after mixing, was poured into cylindrical molds with $\emptyset 35 \mathrm{~mm}$ and $50 \mathrm{~mm}$ height, and kept under sealed condition. At the required age of hydration, the samples were demolded. Using a diamond saw, $4 \mathrm{~mm}$ from the top and bottom of the samples were removed and thrown away. Deionized water was used while cutting the sample to prevent friction and heat. Then three discs with thickness of approximately $2 \mathrm{~mm}$ were cut, one disc was prepared immediately for XRD measurements; the other two were placed in a plastic container and submerged into isopropanol to stop the hydration by solvent exchange. The isopropanol was replaced after one and three days. At 7 days, the two discs were removed and vacuum dried for at least 3 days before further preparation for the different techniques.

The development of the phase composition and the degree of hydration was followed by X-ray diffraction and Rietveld refinement. At the required hydration age, the fresh cut disc from the sample was immediately lightly polished with a $1200 \mu \mathrm{m}$ paper, rinsed with deionized water, put in the XRD for measurement (ex-situ measurements). For in-situ measurements the freshly mixed paste was poured in a special sample holder, the top of the sample covered with a Kapton foil (polyamide film with a thickness of about $7 \mu \mathrm{m}$ ) and well-fasten with a steel ring around the sample holder. The sample holder was then placed in the XRD unit, on a heat-sink plate maintained at $20^{\circ} \mathrm{C}$. Scans were made at intervals over 2.5 days (longer term in-situ measurements are not accurate due to the slow drying that can take place through the Kapton $^{\circledast}$ film and the preferred orientation of phases precipitating at the interface between the paste and Kapton ${ }^{\circledR}$ film. Both in-situ and exsitu measurements were carried out with a PANalytical X'Pert Pro diffractometer with $\mathrm{CuKa}_{1,2}$ radiation in $\theta-\theta$ reflection configuration between 7 and $70^{\circ} 2 \theta$ with step size $0.017^{\circ} 2 \theta$ and $29.8 \mathrm{~s}$ of accumulated time per step. The X-ray tube was at $45 \mathrm{kV}$ and $40 \mathrm{~mA}$, and the incident divergence slit was fixed at $0.5^{\circ}$. The total measurement time per scan was approximately $15 \mathrm{~min}$. The scans were analysed using X'Pert High Score Plus v3.0e software package by PANalytical; phase identification and Rietveld refinement [27-29] were carried out on each scan; the external standard method [30] was used for quantification.

Thermogravimetry (TG) $\left(10{ }^{\circ} \mathrm{C} / \mathrm{min}\right.$ from $30^{\circ} \mathrm{C}$ to $950{ }^{\circ} \mathrm{C}$ in a $30 \mathrm{ml} /$ min flow of nitrogen) was used to follow the development of bound water and calcium hydroxide (Mettler Toledo TGA/SDTA 851). Portions of the solvent exchanged and dried discs were crushed, ground into fine powder and immediately $50 \mathrm{mg}$ was placed in the TG alumina crucibles. The crucibles were covered by an aluminium lid to minimize carbonation prior to measurement.

For mercury intrusion porosimetry (Thermo Scientific ${ }^{\mathrm{TM}}$ 140/440 Pascal) approximately 10 pieces, $5-10 \mathrm{~mm}$ of UHPFRC paste weighing $1.5 \mathrm{~g}$ were taken from the discs stopped by solvent exchange, and inserted in the dilatometer. The maximum MIP pressure was $400 \mathrm{MPa}$. The Washburn equation was used to calculate the equivalent pore radii; the mercury contact angle was taken as $140^{\circ}$ and the surface tension as $0.48 \mathrm{~N} / \mathrm{m}$. More information about the method can be found [31,32].

Compressive strength tests were carried out according to EN 196-1 on $40 \mathrm{~mm}$ cube samples cut from $40 \mathrm{~mm} \times 40 \mathrm{~mm} \times 160 \mathrm{~mm}$ prisms. The mix design proportion is given in Table 1 . Four samples were tested 
a)

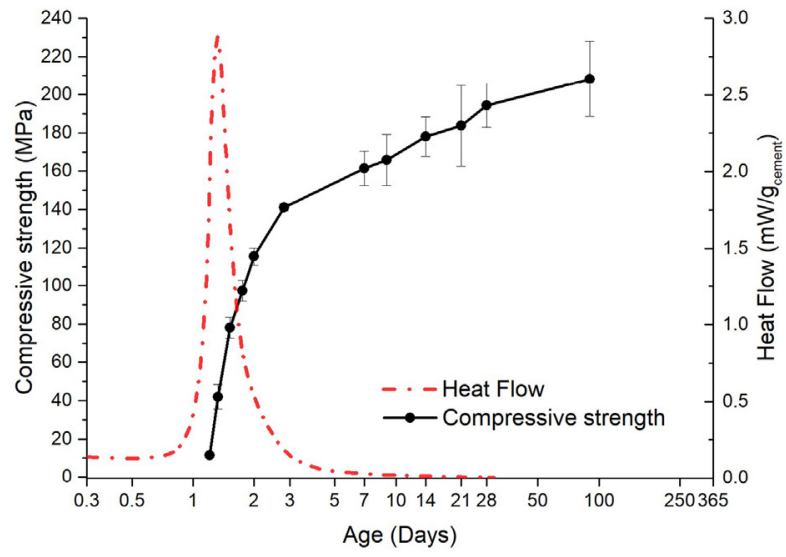

b)
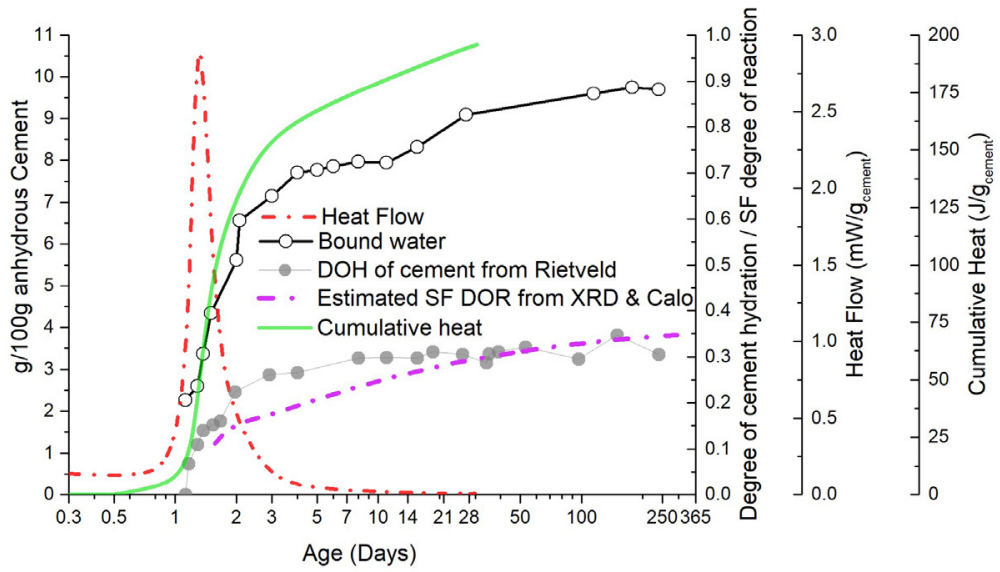

c)

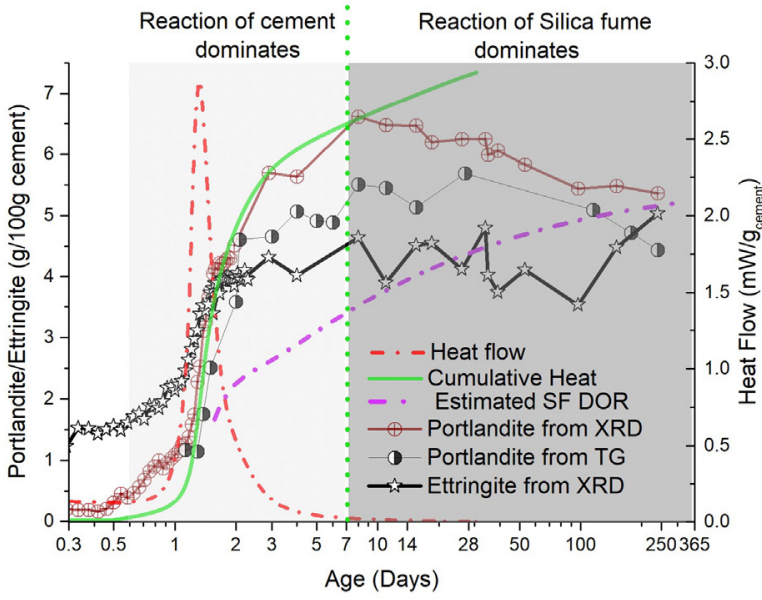

d)

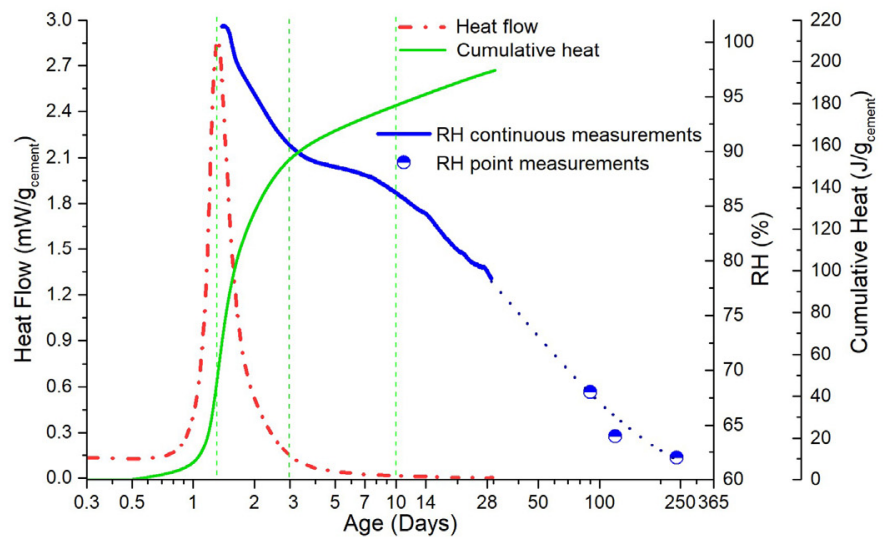

Fig. 2. a) Compressive strength development of the UHPFRC paste along with heat flow from isothermal calorimetry (age axis is in logarithmic scale); b) development of bound water of the UHPFRC paste evaluated from the differential thermal gravimetric (DTG) curves of thermogravimetric (TG) experiments, degree of cement hydration from XRD Rietveld analysis, heat flow and cumulative heat from isothermal calorimetry, and silica fume degree of reaction estimated using the method described in Kazemi Kamyab [33]; c) Portlandite and ettringite contents evaluated from XRD Rietveld. In-situ measurements were made up to the age of $30 \mathrm{~h}$, after which ex-situ point measurements were made. The Portlandite content is also shown as calculated by DTG and the silica fume degree of reaction using the method described in Kazemi Kamyab [33]. For visual guide of their development, heat flow development from isothermal calorimetry has also been shown (the $\mathrm{x}$-axis is in log scale); d) internal relative humidity evolution due to hydration in the UHPFRC paste. 
at each age. The prisms were demolded after 2 days and kept under sealed conditions. The loading rate was $1.50 \mathrm{KN} / \mathrm{s}$.

\section{Results}

The temporal development of all the main results is summarized in Fig. 2 to allow easier comparison between different measurements.

\subsection{Strength and heat development}

Fig. 2a shows the development of the strength and heat flow as function of age on a log scale. It can be seen that the induction period in this UHPFRC is long, due to the high dosage of superplasticizer. The induction period ends around $20 \mathrm{~h}$ after which the main heat release due to calcium silicate reaction starts. The setting time measured by the Vicat test was approximately $28 \mathrm{~h}$. The main peak of hydration is located at approximately $32 \mathrm{~h}$ after mixing. Due to the low $\mathrm{C}_{3} \mathrm{~A}$ content of the cement used, there was no 2nd shoulder peak evident associated with the aluminate reaction. From Fig. 2a, it can be seen that the strength development was delayed due to the retarding effect of superplasticizer. At the peak of the heat flow of the isothermal calorimetry (1.3 days), the compressive strength was $41 \mathrm{MPa}$. Thereafter the strength continues to increase rapidly, reaching $115 \mathrm{MPa}$ at 2 days. After the end of the main hydration heat peak, the rate of strength increase slows down. The UHPFRC reached $162 \mathrm{MPa}$ at 7 days, $195 \mathrm{MPa}$ at 28 days and $208 \mathrm{MPa}$ at 90 days. These very high strengths were obtained under sealed conditions and curing at $20^{\circ} \mathrm{C}$.

\subsection{Phase assemblage}

The thermogravimetric (TG) and differential thermogravimetric (DTG) curves obtained at various ages of hydration were used to evaluate the development of bound water in C-S-H and in aluminate phases, as well as in calcium hydroxide. The water loss up to $400{ }^{\circ} \mathrm{C}$ was taken as the dehydration of C-S-H, AFt and AFm phases, and hereafter is referred to as "bound water". The mass loss between $400{ }^{\circ} \mathrm{C}$ and $500{ }^{\circ} \mathrm{C}$ was attributed to the dehydroxylation of calcium hydroxide $(\mathrm{CH})$. The content of bound water and calcium hydroxide in the sample are shown in Fig. 2c and d, as normalized to the anhydrous cement mass.

Rietveld refinement was carried out on the X-ray diffraction profiles to quantify the phase development of calcium hydroxide and ettringite and to calculate the cement degree of hydration using Eq. (1). The degree of reaction of silica fume was estimated based on calorimetry and XRD results using the method described in Kazemi Kamyab [33]. All results are shown in Fig. 2.

$\operatorname{DOH}(t)=1-\frac{\left.\left(\mathrm{C}_{3} \mathrm{~S}\right)+\mathrm{C}_{2} \mathrm{~S}+\mathrm{C}_{3} \mathrm{~A}+\mathrm{C}_{4} \mathrm{AF}\right)(t)}{\left.\left(\mathrm{C}_{3} \mathrm{~S}\right)+\mathrm{C}_{2} \mathrm{~S}+\mathrm{C}_{3} \mathrm{~A}+\mathrm{C}_{4} \mathrm{AF}\right)(t=0)}$

From the end of the induction period (around $20 \mathrm{~h}$ ), the degree of cement hydration increases rapidly within the next $24 \mathrm{~h}$ (Fig. 2b). During the same period (1-2 days), there is a rapid increase in bound water, in Portlandite content and in ettringite content, following the trend of heat and compressive strength developments. The ettringite content reaches a maximum of $4 \mathrm{~g}$ of ettringite $/ 100 \mathrm{~g}$ of cement at 2 days of hydration, after which it remains stable.

From 2 to 7 days, the degree of cement hydration increases slowly to reach 0.32 at 7 days. The same trend can be observed for the Portlandite content. During this time period, the silica fume also starts to react, reaching a degree of reaction estimated at 0.23 by the age of 7 days (Fig. 2b).

From 7 days on, the degree of cement hydration does not seem to increase significantly while the bound water content, the cumulative heat and the compressive strength continue to increase. This is due to the reaction of silica fume. As a result, the Portlandite content goes down from 6.6 to $5.4 \mathrm{~g}$ of Portlandite $/ 100 \mathrm{~g}$ of cement from 7 to 250 days.
From the following observations (Fig. 2b and c), two main regimes can be identified. In the first 7 days, the hydration is dominated by the clinker hydration. After 7 days, the increase in bound water and strength comes from the reaction of the silica fume.

\subsection{Relative humidity}

The internal relative humidity (RH) of the UHPFRC paste was followed continuously up to 30 days, and then punctual measurements were made at 3 months, 4 months and 8 months (Fig. 2d). Three regimes can be identified. First there is a fast decrease of RH corresponding to the main peak of hydration up to 3 days followed by a plateau from 3 to 7 days at $90 \%$ to $87 \% \mathrm{RH}$. After about 7 days the $\mathrm{RH}$ starts to decrease again, although fairly slowly (considering the $\mathrm{RH}$ is against $\log$ time). At the age of 30 days, the $\mathrm{RH}$ reaches a value of $78.5 \%$ and 8 months, $62 \%$.

Note that the measured $\mathrm{RH}$ is a combination of the decrease of the $\mathrm{RH}$ due to the consumption of the water by the reaction of cement and silica fume and the depression of the water activity due to the ionic concentration. This later effect accounts for an RH decrease of about $2 \%$ [34]. The RH reaches approximately $78 \%$ by 28 days and continues to decrease down to $62 \%$ at 250 days. After 7 days it is clear that the decrease in $\mathrm{RH}$ is mainly due to the reaction of silica fume.

\subsection{Pore structure analysis by MIP}

The pore network evolution was characterized using MIP (Fig. 3). The two main parameters extracted from MIP analysis (Fig. 3b) were total pore volume intruded by the mercury at the maximum applied pressure, expressed in \% of the bulk volume of the sample, and critical pore radius, which is the pore size where the steepest slope of the cumulative intrusion curve is recorded. The critical pore radius is a good indicator of the transport properties of the material.

The total porosity decreases continuously as a function of hydration age (Fig. 3). At the setting time of $28 \mathrm{~h}$, the total porosity is $24 \%$. Thereafter, the total porosity rapidly decreases up to the age of 3 days as hydration products are formed, consuming the water and filling the space. There is a continuous but small decrease in total porosity from 3 to 7 days of age, after which the decrease accelerates again, when the reaction of silica fume dominates. The total mercury penetrable porosity is $6.5 \%$ at 35 days and $2.85 \%$ at 115 days, which is extremely low compared to conventional cement pastes $(12.3 \%$ at 28 days for water to cement ratio of 0.4 [35]).

The critical pore radius goes quickly down to $8 \mathrm{~nm}$ and remains between 5 and $6 \mathrm{~nm}$ up to 28 days. A steep decrease of the critical pore radius is recorded further between 28 and 35 days. The critical pore radius is $1.5 \mathrm{~nm}$ at 115 days.

\section{5. ${ }^{1} H$ NMR relaxometry}

Fig. 4 shows the ${ }^{1} \mathrm{H}$ NMR results and the evolution of the CPMG $T_{2}$ populations corresponding to different liquid water components as a function of hydration time. The signal assignment was done according to the work of [21] whose data is shown for comparison in the figure. It is assumed that the ferrite content of the cement does not influence significantly the relaxation phenomena, as confirmed by other NMR studies of grey cement [36]. The spectra are mainly composed of peaks corresponding to the water in the C-S-H interlayer space $\left(T_{2}=100 \mu \mathrm{s}\right)$ and to water in the C-S-H gel pore spaces $T_{2} \approx 300 \mu \mathrm{s}$ $\left(T_{2}=250-800 \mu \mathrm{s}\right)$. Already at $31 \mathrm{~h}(3 \mathrm{~h}$ after setting by Vicat needle), there are only very small peaks corresponding to water in large capillary pores $\left(T_{2}>1 \mathrm{~ms}\right)$.

Fig. 5a shows the evolution of the integrated peak areas of the NMR $T_{2}$ peak distribution shown in Fig. 4 for the different water populations as a function of time for the UHPFRC paste. At the top, the solid signal from $\mathrm{QE}$ experiments corresponding to water bound in crystalline 

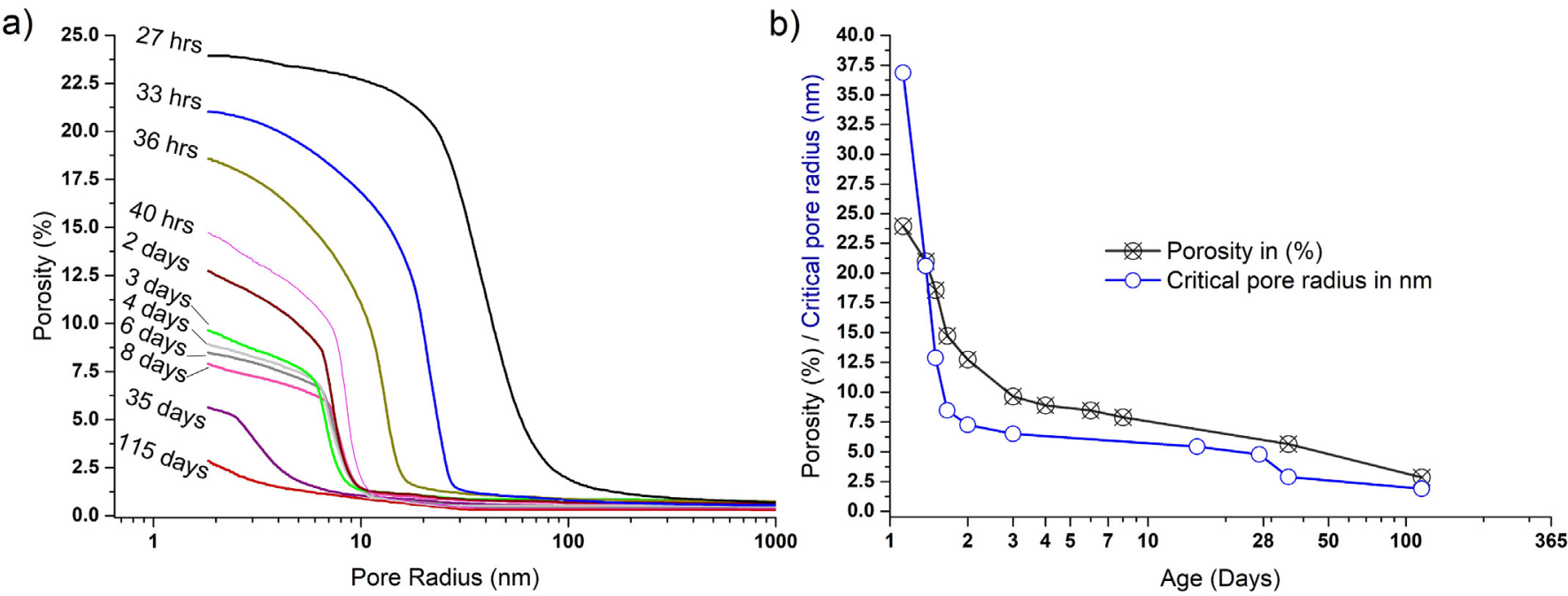

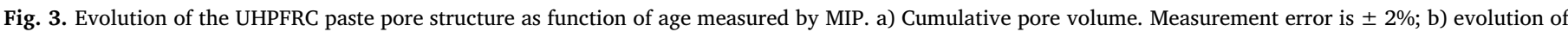
the total porosity and critical pore radius in the UHPFRC paste as function of hydration age.

phases Portlandite and ettringite is shown. These are NMR signal fractions of the total NMR response registered at time of mixing. The different calculated signal fractions can therefore be considered as absolute water mass fractions [21]. The evolution for the white cement paste prepared with $w / c=0.4$ from [21] is also shown for comparison. Fig. 6 shows the NMR signal evolution from 0 to 3 days on a linear scale.

\section{- Induction period}

During the induction period, there is a small increase of signal associated with C-S-H interlayer water and water in crystalline solid phases. This is associated with the precipitation of ettringite [37] and the nucleation of small amounts of CH and C-S-H hydrates [38] as seen by other methods such as SEM imaging [12]. The results from XRD confirm that ettringite is formed from the very early ages reaching $50 \%$ of its final content already before the measured setting time. The same can be observed in the case of Portlandite where there is already $1.2 \mathrm{~g}$ of Portlandite $/ 100 \mathrm{~g}$ of cement formed during the induction period (Fig. 2c). This supports the fact that there is some solid and C-S-H interlayer water present from soon after the mixing so that the capillary water does not start from $100 \%$ in ${ }^{1} \mathrm{H}$ NMR results.

\section{- Acceleration period (1d-31 h)}

At the end of the induction period the capillary water starts to be rapidly consumed decreasing from $85 \%$ at $23 \mathrm{~h}$ to $3.7 \pm 2 \%$ at $31 \mathrm{~h}$, which corresponds to the main hydration peak and to the end of the acceleration period seen by isothermal calorimetry. During the acceleration period, signals from both solid water and from the C-S-H interlayer water increase. Over the same period of time the signal corresponding to the C-S-H gel water goes rapidly from a negligible signal at the end of the induction period to $57 \% \pm 5 \%$ of the mixing water at the end of the acceleration period. The rate of increase of the C-S-H gel

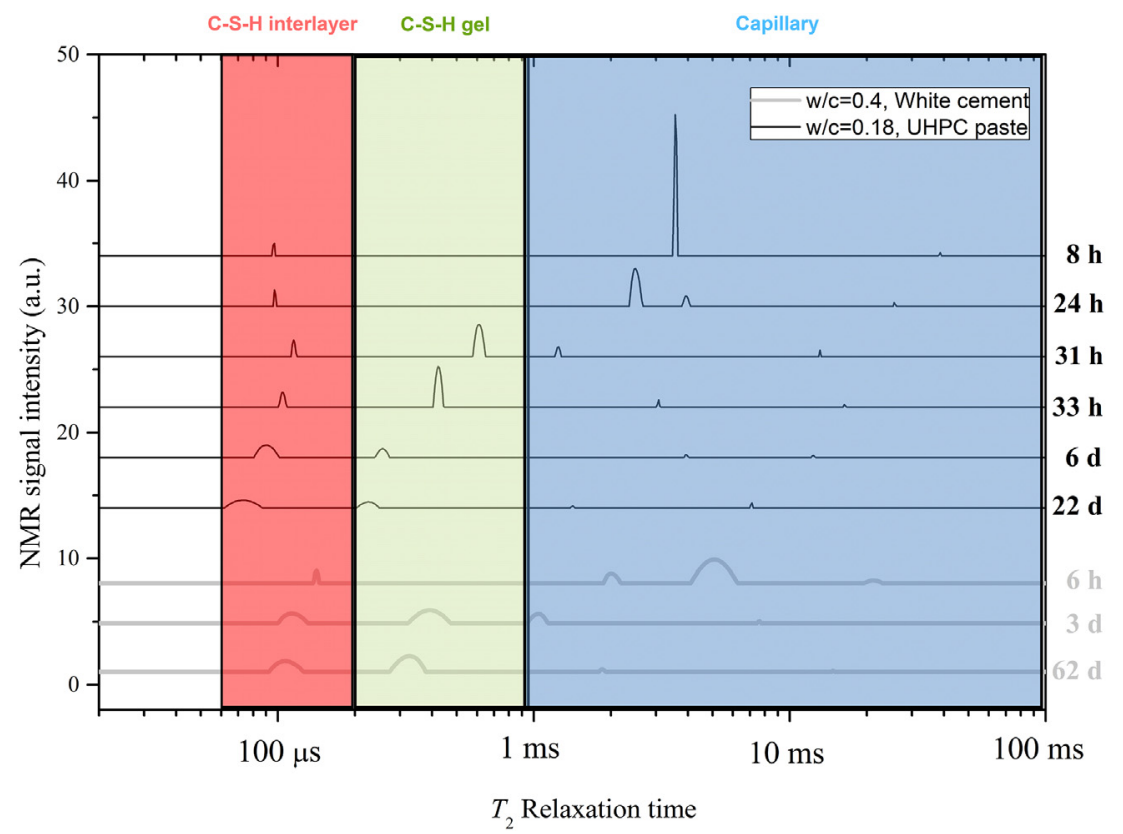

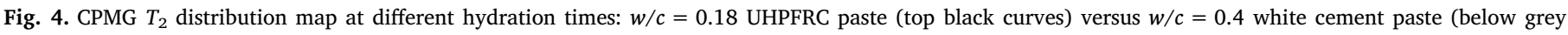
curves). 
a)

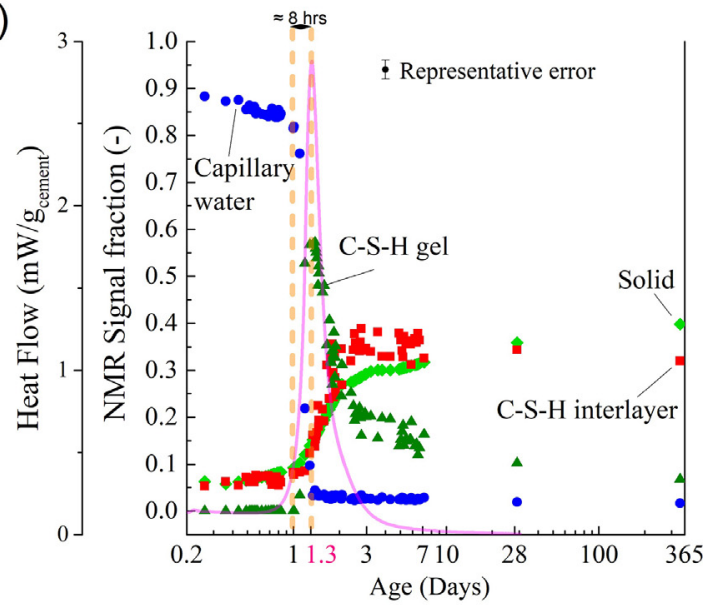

c)

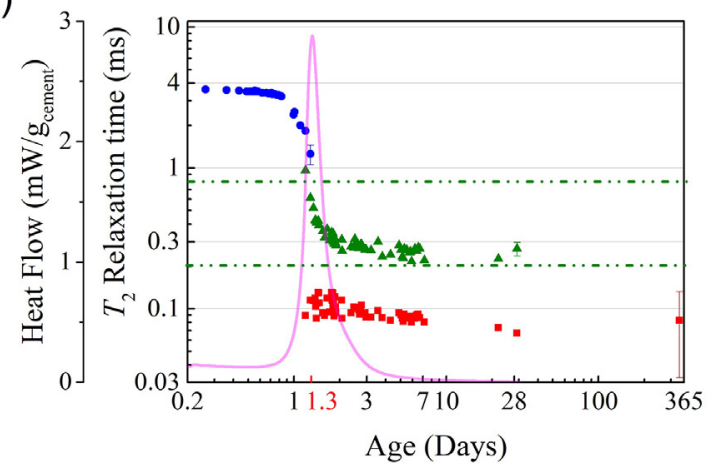

b)

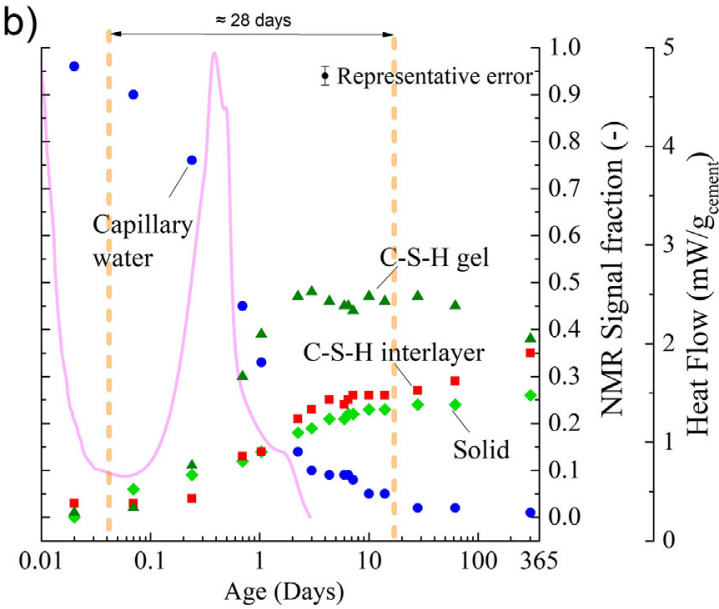

d)

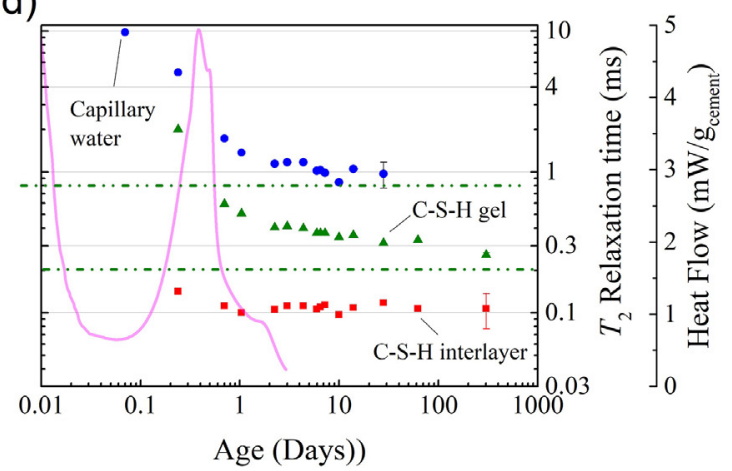

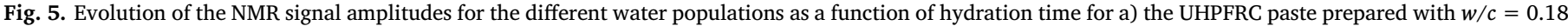

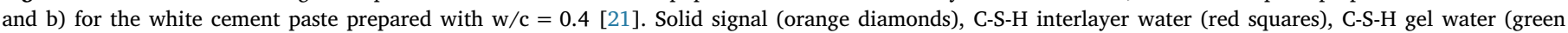

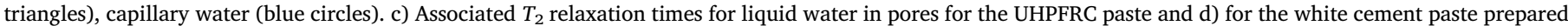

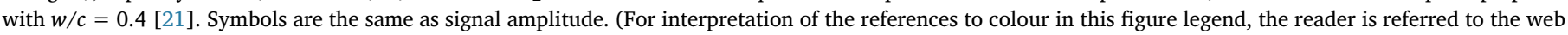
version of this article.)

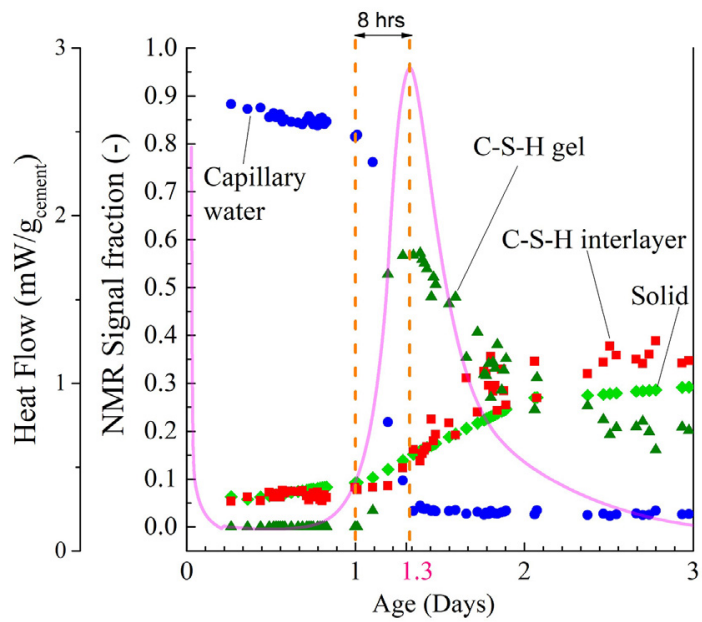

Fig. 6. Evolution of the signal amplitudes for the different water populations as a function of hydration time (linear scale) for the UHPFRC paste up to 3 days of hydration. The absolute error for the capillary and solid signal fraction is $\pm 2 \%$ while that of C-S-H signals are $\pm 5 \%$.

water is much faster than the rate of increase of the C-S-H interlayer water and of the water in crystalline phases (Portlandite and ettringite).

- Deceleration period (31 h-3d)
At the peak of hydration $(31 \mathrm{~h})$, the capillary water has nearly been entirely consumed and remains constant at a few \% afterwards. After having reached a maximum of $57 \% \pm 5 \%$ at the end of the acceleration period, the content of C-S-H gel water sharply decreases until the end of the deceleration period ( 3 days), after which it decreases much more slowly. During the deceleration period the signal from solid water and $\mathrm{C}-\mathrm{S}-\mathrm{H}$ interlayer water continue to increase.

\section{- Long term $(3 \mathrm{~d}-1 \mathrm{y})$}

Beyond 3 days, the hydration evolves much more slowly using up the gel water. The signal from the C-S-H interlayer water remains flat while the NMR solid signal continues to slowly increase. This will be further discussed in the Discussion section. At about 1 year, the solid water signal accounts for $40 \% \pm 5 \%$ of the mixing water while the C-S$\mathrm{H}$ gel water has decreased down to $7 \% \pm 5 \%$ at 1 year.

Fig. $5 \mathrm{c}$ shows the associated $T_{2}$ relaxation times for the different liquid water populations: C-S-H interlayer water, C-S-H gel water and the capillary pore water for the UHPFRC paste. Fig. $5 \mathrm{~d}$ shows the results for the white cement paste prepared with $w / c=0.4$ from MULLER et al. For the UHPFRC paste, the signal is initially dominated by the free water with long $T_{2}$ at around $3.5 \mathrm{~ms}$. At the end of the induction period and along with the consumption of capillary water, this rapidly falls and the associated $T_{2}$ of the capillary water reaches a value of $1.3 \mathrm{~ms}$ before becoming very small at the end of the acceleration period. This reflects the refinement of the capillary porosity as hydration takes place. As there is little capillary water at later ages ( $<4 \%$ of the total water), it is difficult to accurately measure the corresponding $T_{2}$. 
Therefore no further $T_{2}$ for the capillary water beyond 1.3 days is reported.

The $T_{2}$ associated with the C-S-H gel water exhibits a progressive decrease from $800 \pm 50 \mu$ s at the time it first appears down to a value of $250 \pm 50 \mu$ s at 7 days of hydration. This indicates a decrease in size of the water filled CSH gel pores with time, which was also observed for the white cement paste prepared with $w / c=0.40$, even though on a much longer timescale.

The $T_{2}$ of the C-S-H interlayer water goes slightly down with hydration time from $T_{2}=100 \mu$ s between 1 and 3 days to around $70 \pm 20 \mu$ s after 28 days of hydration. The order of magnitude is similar to what was observed for $T_{2}$ of the interlayer water in the white cement paste prepared with $w / c=0.40$, even though no decrease was reported for the conventional paste.

Muller et al. [39] used the fast exchange model [40] to relate the $T_{2}$ relaxation times to pore sizes. As the same NMR spectrometer and parameters were used in this study, we believe that the same surface relativity parameter can be applied to calculate pore sizes in UHPFRC paste. It corresponds to $\lambda=3.71 \times 10^{-3} \mathrm{~nm} / \mu \mathrm{s}$. Using this value, the capillary pore size at the time it last appears (1.3 days) is $9 \mathrm{~nm}$. The calculated size for the C-S-H gel pores that still contain water, goes progressively down from initially $5 \mathrm{~nm}$ to $2.5 \mathrm{~nm}$ at 7 days of hydration. For the C-S-H interlayer space, $100 \mu$ s corresponds to a size of $0.85 \mathrm{~nm}$, which is exactly what was reported for C-S-H in white cement pastes.

\section{Discussion}

In cement pastes at conventional water to cement ratios $(\sim 0.4)$ several kinetic regimes are identified. First, there is the classical growth of hydrates with consumption of water and reduction of porosity. After a few days, there comes a point where the size of the capillary pores does not decrease further (interhydrates), and there is no more increase of the water in gel pores [39]. Then, there is a long period in which the amount of water in gel pore remains more of less constant, but, as more $\mathrm{C}-\mathrm{S}-\mathrm{H}$ is forming, the average density of the C-S-H increases. Finally, after several months the amount of water in the gel pores starts to decrease. Because of the low amount of water and space available for hydration, the UHPFRC paste goes much more quickly through these different phases. At the peak of the calorimetry curve, the capillary pores have already decreased to the interhydrate size and the capillary water is almost entirely consumed. Then, rather than stabilizing, the amount of water in the gel pores decreases rapidly indicating that hydration continues by using up the gel pore water. In parallel, we observed that the compressive strength and the bound water go up as a result of further cement and silica fume hydration. By the end of the main hydration peak, the ratio of gel to interlayer water is only about 0.5 and drops to around 0.2 at 8 months in contrast to around 1.5 to 2 in conventional pastes during the first month or so. It is not clear whether the water in the gel pores is just being consumed to form C-S-H elsewhere or if the gel pores are actually being filled with C-S-H. The MIP results suggest the former as the pore volume measured by MIP keeps on decreasing up to the end of the measurements period. The porosity measured by MIP at 115 days is $2.85 \%$ and the critical diameter is down to $1.5 \mathrm{~nm}$. This means that the capillary pores have been filled up to a point where there are almost no capillary pores left that MIP can penetrate.

One other important result of this paper is that in the long term the NMR solid signal is clearly more than can be explained by the water content of the crystalline phases. To demonstrate this, Fig. 7 shows the calculated NMR solid signal based on XRD ettringite + Portlandite water content as compared to the solid signal measured for the UHPFRC paste. This unusual rise in NMR solid signal suggests that some of the inter-layer water of (relatively) late forming C-S-H manifests as "solid water" signal and not as "inter-layer water". This was rarely observed for conventional $\mathrm{w} / \mathrm{c}$ pastes, only sometimes in the very long term [42]. It might also suggest that the water in $\mathrm{C}-\mathrm{S}-\mathrm{H}$ layers is becoming more

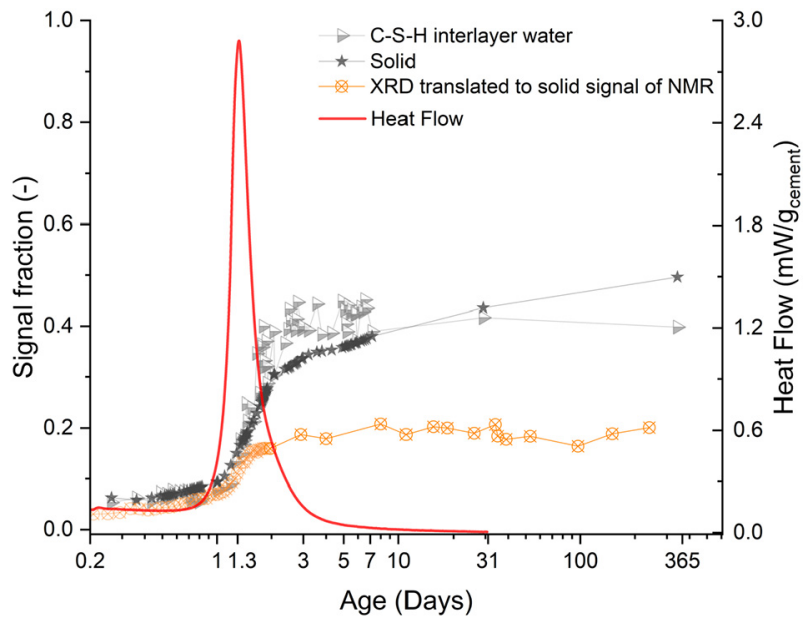

Fig. 7. Comparison between the rise in solid signal from UHP paste and the solid signal as calculated from XRD Portlandite + ettringite water.

confined than in conventional cement paste where water is still available in capillary pores. The progressive decrease over time in $\mathrm{T} 2$ of the interlayer water from $100 \mu$ s to $70 \mu$ s is another indication that C-S-H interlayer water in UHPFRC paste is somehow more confined. At this stage, it is impossible to tell if the inter-layer spacing of the lately formed C-S-H is reduced, or if the measurement of shorter T2 is a consequence of the strong desiccation so that the water cannot move around (exchange) as freely as before. In either case it is indication of a higher degree of water confinement within the sample studied.

The relative humidity results show that the UHPFRC paste under investigation is quickly under extreme self-desiccation. Earlier studies reported that the hydration of the clinker phases stops below $80 \% \mathrm{RH}$ [43-45]. The same can be observed in the present study where there is very little clinker reaction after 7 days and none after 28 days when the $\mathrm{RH}$ decreases below $80 \%$. On the other hand, it is noticeable that silica fume does continue to react in the low $\mathrm{RH}$ environment, enhancing the strength. This is clearly an area where more study is needed.

\section{Conclusions}

The evolution of the state of water in a UHPFRC paste was followed by ${ }^{1} \mathrm{H}$ NMR leading to the following findings:

- The different water populations and pore size classes are similar to conventional pastes but because of the low $w / c$, the UHPFRC paste consumes very quickly the capillary water and the hydration continues using the gel water from as early as $8 \mathrm{~h}$ after the setting time.

- XRD, calorimetry and TGA measurements showed that the hydration is dominated by the hydration of the clinker up to around 7 days.

- Subsequently the reaction of the silica fume plays the major role by further using the gel water to form more C-S-H. This leads to a further increase in compressive strength, even with low internal $\mathrm{RH}$.

- MIP showed a pore volume of $2.85 \%$ at 115 days.

- NMR result showed that some of the C-S-H formed in UHPFRC paste have much more confined water than in conventional cement pastes.

\section{Declaration of Competing Interest}

The authors declare that they have no known competing financial interests or personal relationships that could have appeared to influence the work reported in this paper. 


\section{Acknowledgments}

The first author acknowledges the financial support from the European community through Marie Curie ITN - FP7 within the TEAM project. This study benefitted from the support of the staff and the facilities of the Laboratory of Construction Materials (LMC) at EPFL.

\section{References}

[1] F. Toutlemonde, J. Resplendino, Designing and Building With UHPFRC: From Innovation to Large-scale Realizations: Proceedings of the RILEM-fib-AFGC International Symposium on Ultra-high Performance Fibre-reinforced Concrete, Marseille, France, October 1-3, 2013, (2013).

[2] M. Bastien-Masse, E. Denarié, E. Brühwiler, Effect of fiber orientation on the inplane tensile response of UHPFRC reinforcement layers, Cem. Concr. Compos. 67 (2016) 111-125.

[3] K. Wille, S. El-Tawil, A.E. Naaman, Properties of strain hardening ultra high performance fiber reinforced concrete (UHP-FRC) under direct tensile loading, Cem. Concr. Compos. 48 (2014) 53-66.

[4] E. Denarié, E. Brühwiler, Cast-on site UHPFRC for improvement of existing struc tures-achievements over the last 10 years in practice and research, 7th Workshop on High Performance Fiber Reinforced Cement Composites, 1-3, June 2015, Stuttgart, Germany, 2015.

[5] N. Roux, C. Andrade, M. Sanjuan, Experimental study of durability of reactive powder concretes, J. Mater. Civ. Eng. 8 (1996) 1-6.

[6] F. De Larrard, Concrete Mixture Proportioning: A Scientific Approach, CRC Press, 1999.

[7] H.H. Bache, Densified cement ultra-fine particle-based materials, Second International Conference on Superplasticizers in Concrete, 1981 (Ottawa, Ontario, Canada).

[8] P. Richard, M. Cheyrezy, Composition of reactive powder concretes, Cem. Concr. Res. 25 (1995) 1501-1511.

[9] P. Lu, G. Sun, J.F. Young, Phase composition of hydrated DSP cement pastes, J. Am. Ceram. Soc. 76 (1993) 1003-1007.

[10] C. Porteneuve, J.-P. Korb, D. Petit, H. Zanni, Structure-texture correlation in ultrahigh-performance concrete: a nuclear magnetic resonance study, Cem. Concr. Res. 32 (2002) 97-101.

[11] H. Zanni, M. Cheyrezy, V. Maret, S. Philippot, P. Nieto, Investigation of hydration and pozzolanic reaction in Reactive Powder Concrete (RPC) using 29Si NMR, Cem. Concr. Res. 26 (1996) 93-100.

[12] E. Berodier, K. Scrivener, Understanding the filler effect on the nucleation and growth of C-S-H, J. Am. Ceram. Soc. 97 (2014) 3764-3773.

[13] W.A. Gutteridge, J.A. Dalziel, Filler cement: the effect of the secondary component on the hydration of Portland cement: part I. A fine non-hydraulic filler, Cem. Concr. Res. 20 (1990) 778-782.

[14] P. Lawrence, M. Cyr, E. Ringot, Mineral admixtures in mortars: effect of inert materials on short-term hydration, Cem. Concr. Res. 33 (2003) 1939-1947.

[15] J.J. Thomas, H.M. Jennings, J.J. Chen, Influence of nucleation seeding on the hydration mechanisms of tricalcium silicate and cement, J. Phys. Chem. C 113 (2009) 4327-4334.

[16] O. Bonneau, C. Vernet, M. Moranville, P.-C. AiTcin, Characterization of the granular packing and percolation threshold of reactive powder concrete, Cem. Concr. Res. 30 (2000) 1861-1867.

[17] V. Morin, F. Cohen-Tenoudji, A. Feylessoufi, P. Richard, Evolution of the capillary network in a reactive powder concrete during hydration process, Cem. Concr. Res. 32 (2002) 1907-1914.

[18] S.A. Touse, T.A. Bier, C.A. Knepfler, J.F. Young, R.L. Berger, Pore structure of low porosity DSP cement pastes, MRS Online Proc. Libr. 137 (1988) (null-null).

[19] J.P. Korb, D. Petit, S. Philippot, H. Zanni, V. Maret, M. Cheyrezy, Nuclear relaxation of water confined in reactive powder concrete, in: P. Colombet, H. Zanni, A.-
R. Grimmer, P. Sozzani (Eds.), Nuclear Magnetic Resonance Spectroscopy of Cement-Based Materials, Springer, Berlin Heidelberg, 1998.

[20] A. Valori, P.J. Mcdonald, K.L. Scrivener, The morphology of C-S-H: lessons from 1H nuclear magnetic resonance relaxometry, Cem. Concr. Res. 49 (2013) 65-81.

[21] A. Muller, K. Scrivener, A. Gajewicz, P. Mcdonald, Use of bench-top NMR to measure the density, composition and desorption isotherm of $\mathrm{C}-\mathrm{S}-\mathrm{H}$ in cement paste, Microporous Mesoporous Mater. 178 (2013) 99-103.

[22] K. Scrivener, R. Snellings, B. Lothenbach, A Practical Guide to Microstructural Analysis of Cementitious Materials, Crc Press, 2018.

[23] J. Powles, J. Strange, Zero time resolution nuclear magnetic resonance transient in solids, Proc. Phys. Soc. 82 (1963) 6.

[24] S. Meiboom, D. Gill, Modified spin-echo method for measuring nuclear relaxation times, Rev. Sci. Instrum. 29 (1958) 688-691.

[25] P.J Mcdonald, V. Rodin, A. Valori, Characterisation of intra-and inter-C-S-H gel pore water in white cement based on an analysis of NMR signal amplitudes as a function of water content, Cement and Concrete Research 40 (2010) 1656-1663.

[26] L. Venkataramanan, Y.-Q. Song, M.D. Hürlimann, Solving Fredholm integrals of the first kind with tensor product structure in 2 and 2.5 dimensions, IEEE Trans. Signal Process. 50 (2002) 1017-1026.

[27] M.A.G. Aranda, A.G. De La Torre, L. León-Reina, Rietveld quantitative phase analysis of OPC clinkers, cements and hydration products, Rev. Mineral. Geochem. 74 (1) (2012) 169-209.

[28] R. Snellings, A. Bazzoni, K. Scrivener, The existence of amorphous phase in Portland cements: physical factors affecting Rietveld quantitative phase analysis, Cem. Concr. Res. 59 (2014) 139-146.

[29] R. Snellings, L. Machiels, G. Mertens, J. Elsen, Rietveld Refinement Strategy for Quantitative Phase Analysis of Partially Amorphous Zeolitized Tuffaceous Rocks, Geologica belgica, 2010 .

[30] D. Jansen, F. Goetz-Neunhoeffer, C. Stabler, J. Neubauer, A remastered external standard method applied to the quantification of early OPC hydration, Cem. Concr. Res. 41 (2011) 602-608.

[31] E. Berodier, J. Bizzozero, A.C. Muller, Mercury Intrusion Porosimetry, CRC Press, Boca Raton, 2016.

[32] K. Scrivener, R. Snellings, B. Lothenbach, A Practical Guide to Microstructural Analysis of Cementitious Materials, Taylor \& Francis, 2016.

[33] M. Kazemi Kamyab, Autogenous Shrinkage and Hydration Kinetics of SH-UHPFRC Under Moderate to Low Temperature Curing Conditions, EPFL, 2013.

[34] H. Chen, M. Wyrzykowski, K. Scrivener, P. Lura, Prediction of self-desiccation in low water-to-cement ratio pastes based on pore structure evolution, Cem. Concr. Res. 49 (2013) 38-47.

[35] E. Berodier, K. Scrivener, Evolution of pore structure in blended systems, Cem. Concr. Res. 73 (2015) 25-35.

[36] A.C. Muller, J. Mitchell, P.J. Mcdonald, Proton Nuclear Magnetic Resonance Relaxometry, CRC Press, Boca Raton, FL, USA, 2015.

[37] K.L. Scrivener, P. Juilland, P.J.M. Monteiro, Advances in understanding hydration of Portland cement, Cem. Concr. Res. 78 (2015) 38-56.

[38] C. Hesse, F. Goetz-Neunhoeffer, J. Neubauer, A new approach in quantitative in-situ XRD of cement pastes: correlation of heat flow curves with early hydration reactions, Cem. Concr. Res. 41 (2011) 123-128.

[39] A.C. Muller, K.L. Scrivener, A.M. Gajewicz, P.J. Mcdonald, Densification of C-S-H measured by ${ }^{1} \mathrm{H}$ NMR relaxometry, J. Phys. Chem. C 117 (2012) 403-412.

[40] F. D'orazio, S. Bhattacharja, W.P. Halperin, K. Eguchi, T. Mizusaki, Molecular diffusion and nuclear-magnetic-resonance relaxation of water in unsaturated porous silica glass, Phys. Rev. B 42 (1990) 9810-9818.

[41] A.C.A. Muller, Characterization of Porosity \&amp; CSH in Cement Pastes by ${ }^{1} \mathrm{H}$ NMR, (2014).

[42] R.J. Flatt, G.W. Scherer, J.W. Bullard, Why alite stops hydrating below $80 \%$ relative humidity, Cem. Concr. Res. 41 (2011) 987-992.

[43] O.M. Jensen, Thermodynamic limitation of self-desiccation, Cem. Concr. Res. 25 (1995) 157-164.

[44] O.M. Jensen, P.F. Hansen, E.E. Lachowski, F.P. Glasser, Clinker mineral hydration at reduced relative humidities, Cem. Concr. Res. 29 (1999) 1505-1512. 